Int. J. Plant Sci. 164(3 Suppl.):S103-S114. 2003.

(C) 2003 by The University of Chicago. All rights reserved.

$1058-5893 / 2003 / 16403 S-0008 \$ 15.00$

\title{
THE EVOLUTIONARY ECOLOGY OF SPROUTING IN WOODY PLANTS
}

\author{
William J. Bond ${ }^{1}$ and Jeremy J. Midgley ${ }^{2}$ \\ Botany Department, University of Cape Town, Private Bag, Rondebosch 7701, South Africa
}

\begin{abstract}
Woody plants may be killed by severe disturbance or resprout from vegetative tissue. Sprouters can persist at a site through several generations of nonsprouters. Differences in sprouting behavior are therefore important for understanding vegetation dynamics, extinction risks, and woody plant management. Although sprouting appears not to be uniquely correlated with many other intrinsic attributes, such as specific leaf area or breeding systems, a clear correlate is reduced seedling aboveground growth rates from sprouters allocating more to belowground structures. Consequently, sprouters tend to have low seedling recruitment rates, and saplings take longer to reach maturity. Sprouters also tend to have lower seed output than nonsprouters, but comparative studies have seldom taken other trait differences such as plant size into account. Added to these trade-offs between persistence and recruitment, sprouters are often multistemmed and shorter than related nonsprouters and may be outcompeted by them when disturbances are rare. Since sprouters tend to have long generation times, damped demographic trends, and gene flow across generations, it has been suggested that their speciation rates would be low. The available data, primarily from fire-prone Gondwanan shrublands in South Africa, show no strong differences in speciation rates of related sprouters versus seeders. This indicates that ecological factors are important determinants of the evolution of fire life histories. Analysis of disturbance regimes indicates a fundamental ecological correlate: sprouters are favored where disturbance regimes are frequent and severe in comparison to regrowth rates. To bridge the gap between ecology and evolution, data are needed on the genetical differences between related species with contrasting sprouter life histories.
\end{abstract}

Keywords: life history evolution, sprouting, fire ecology, disturbance, plant functional trait.

\section{Introduction}

Woody plants either are killed or resprout from vegetative tissue after severe injury from disturbances such as herbivory, fire, floods, hurricanes, landslides, or logging. The different responses to injury are both ecologically and evolutionarily important. Sprouters can occupy the same space for hundreds to thousands of years and have minimal changes in population size. In contrast, nonsprouters are subject to all the vicissitudes of regeneration from seeds, including pollination and dispersal failure, seedling mortality, and sapling competition. Characterizing sprouting behavior is therefore important for predicting how species will respond in models of vegetation dynamics, in determining extinction risks for threatened species, and in developing utilization methods for woody plant management. Sprouting behavior may also influence global change responses since, for example, sprouters often store considerable amounts of carbon belowground (Langley et al. 2002), which may change their response to $\mathrm{CO}_{2}$ relative to nonsprouters with otherwise similar functional traits. The growing interest in sprouting as a major plant functional trait is reflected in a number of recent reviews on the topic (Bellingham and Sparrow 2000; Bell 2001; Bond and Midgley 2001; Del Tredici 2001). Generalizations have begun to emerge from studies of

\footnotetext{
${ }^{1}$ E-mail bond@botzoo.uct.ac.za.

2 E-mail midgleyj@botzoo.uct.ac.za.

Manuscript received December 2002; revised manuscript received January 2003.
}

sprouting, but these are far less well supported than those based on seed size (Westoby et al. 1996) or SLA (Reich et al. 1992). Sprouting has not been included in general functional type systems such as those of Grime (1979; Grime et al. 1997) or Westoby (1998). There are still many ecosystems and species for which we have no information at all on sprouting as a functional attribute.

In this article, we first characterize sprouting using a recent classification of sprouting mode to help define the considerable variation seen within and among taxa (Del Tredici 2001). We then review ideas on selection regimes likely to favor different modes of sprouting (Ojeda 1998; Bellingham and Sparrow 2000; Bond and Midgley 2001; Del Tredici 2001). There is growing interest in sprouting as a syndrome rather than merely as a trait, with distinct trade-offs between persistence and recruitment. We review ideas and data on life history trade-offs and suggested mechanisms underlying the trade-offs. Ideas on the macroevolutionary consequences of sprouting are becoming testable with the increasing availability of phylogenies of genera for which there is also information on sprouting. We discuss patterns, based on phylogenies of fire-adapted Australian and South African shrubs, on the evolutionary polarity of sprouting and on whether nonsprouting clades speciate more readily. Our analysis is of a preliminary nature and offered in the hope that we might stimulate more work on the topic to address hypotheses on adaptive radiation in disturbance-prone environments. 


\section{Types of Sprouting}

One of the obstacles to using sprouting as a functional trait is the complexity of sprouting behavior. Del Tredici (2001) has provided a particularly lucid account of the morphological basis of sprouting in temperate trees that throws light on the situation. In terms of persistence of an individual, the most useful definition of sprouting is the production of secondary trunks as an induced response to injury or to profound changes in growing conditions. Sprouting differs from clonal growth in that it does not imply the potential for vegetative spread (Del Tredici 2001). Many more species are sprouters than are clonal, though most, if not all, clonal woody species sprout. There is no qualitative difference between sprouting at the base of the plant or sprouting from branches higher in the canopy, but the former is the main focus here (see Burrows 2002 for an analysis of epicormic sprouting in Australian trees).

Del Tredici describes four basic sprouting types: collar sprouts from the base of the trunk, sprouts from specialized underground stems (lignotubers and rhizomes), sprouts from roots (root suckering), and opportunistic sprouts from layered branches.

Collar sprouts are derived from meristematic tissue in the axils of the cotyledons of dicotyledonous seedlings. Buds develop from this tissue with a direct connection to the vascular cylinder. In mature trees, the collar develops at or just below ground level and can be visible as numerous suppressed buds protruding from the trunk. Collar sprouts and suppressed buds are ubiquitous features of temperate angiosperm trees, at least in saplings, but may be lost from mature trees (Del Tredici 2001). Many conifers lack cotyledonary buds and functional collars and typically do not sprout. Some fire-adapted species that lack cotyledonary buds have become sprouters secondarily by evolving the ability to sprout from axillary buds above the cotyledonary node (Keeley and Zedler 1998). A more ancient origin of sprouting in conifers may be present in Sequoia and Cunninghamia in the Taxodiaceae and Taxus and Torreya in the Taxaceae (Del Tredici 2001), all of which develop collars that produce sprouts.

Lignotubers are swollen structures that develop from suppressed buds at the cotyledonary node of seedlings. The structures protrude from the stem (several meters in some cases) so that sprouts typically emerge some distance from the primary stem. The function of lignotubers is still debated (James 1984; Canadell and Lopez-Soria 1998; Lloret et al. 1999). Though they are common in fire environments, they also occur where fires are rare or absent (Lloret et al. 1999). Some lignotubers store large quantities of starch, which is mobilized for sprouting of stems (Canadell and Lopez-Soria 1998). However, in other species, lignotubers are not important for starch storage, and sprouting is not dependent on mobilization of starch from lignotubers (Cruz and Moreno 2001; Wildy and Pate 2002). Their main function seems to be to maintain very large bud banks for continuous (Mesleard and Lepart 1989) or disturbance-induced episodic sprouting.

Root suckering allows sprouting plants to propagate vegetatively, spreading from the original site of establishment. Del Tredici (2001) notes that some root-suckering shrubs produce root suckers spontaneously as part of normal development but that in most temperate trees, especially from mesic habitats,

\section{Table 1}

Sprouting Characteristics in Northeastern North American Trees (ex Del Tredici 2001)

\begin{tabular}{lccc}
\hline Type & Collar sprouting & Root suckering & Nonsprouting \\
\hline Angiosperms: & & & \\
$\quad$ Saplings & 54 & 17 & 0 \\
$\quad$ Adults & 28 & 17 & 26 \\
Conifers: & & 0 & 11 \\
$\quad$ Saplings & 2 & 0 & 13 \\
Adults & 0 & \\
\hline
\end{tabular}

Note. Values are numbers of species. Seedlings of all species were capable of collar sprouting.

root suckering is an induced response to injury such as from fire or logging.

Finally, many woody species are capable of producing adventitious roots from lateral branches that come in contact with the soil. Clearly, the branching architecture will strongly influence the frequency and ecological importance of layering as a form of sprouting and vegetative spread (see Feild et. al 2003). We do not further discuss layering in this article.

Table 1 shows sprouting characteristics of northeastern United States deciduous trees, based on Del Tredici's four sprouting types. We know of no other classifications of sprouting behavior in a flora as comprehensive as Del Tredici's analysis of temperate deciduous tree species. Lignotubers are common in many fire-prone ecosystems (James 1984) but also occur in shrublands where fire is unknown (Lloret et al. 1999). Root suckering is common in understory woody plants in temperate forests (Del Tredici 2001) and in some mesic savanna woodlands (Strang 1974), but it is comparatively rare in fireprone shrublands (W. J. Bond and J. J. Midgley, personal observation).

\section{Ontogenetic Variation in Sprouting Characteristics}

Sprouting ability varies with the age or size of a plant and also with the type and severity of injury (Hodgkinson 1998; Bellingham and Sparrow 2000; Bond and Midgley 2001). All angiosperm tree species in Del Tredici's sample are capable of sprouting from seedling to sapling stage, but many lose the ability to sprout as adults (table 1). Most conifers, in contrast, sprout only as seedlings and do not sprout as saplings or adults. Clearly, the ecological implications of sprouting differ depending on ontogenetic changes in sprouting behavior (Hodgkinson 1998) and whether resprouting is associated with the ability to spread beyond the parent plant by vegetative means such as root suckering. In fire-prone shrublands, sprouting is usually described as a binary trait that embraces sprouters and "seeders," with some subdivision of sprouting depending on the frequency of seedling production (Bell et al. 1984; Keeley 1986). In tropical and temperate forests, binary classifications are more difficult because of size-dependent variation in sprouting and variation due to the severity of disturbance.

Sprouting ability can be important as part of both the regeneration niche (Grubb 1977) and the persistence niche (Bond and Midgley 2001). The regeneration niche concerns factors influencing the probability of juveniles recruiting successfully in different environmental settings. For example, variation in 
sprouting ability at the seedling stage, according to some recent studies, plays a greater role in deciduous forest dynamics than interspecific variation in seedling and sapling growth rate, especially under shady conditions (Canham et al. 1999). The persistence niche concerns factors that influence the probability of an established plant maintaining its space in a community without seedling recruitment. For questions where persistence of established mature plants is the main concern, we suggest using adult sprouting behavior as the most useful functional descriptor of sprouting.

\section{Evolution of Sprouting}

Interest in evolutionary aspects of sprouting was sparked by a seminal paper by Wells (1969). He noted that members of most woody genera in Californian chaparral recover from periodic fires by sprouting. However, the two largest genera, Ceanothus (Rhamnaceae) and Arctostaphylos (Ericaceae), include both sprouting and nonsprouting species, with the latter making up nearly $80 \%$ of the taxa in both genera. Wells noted that both life history strategies produced seedlings, typically only after a fire. However, populations of sprouters recover from fire mostly by vegetative means, whereas nonsprouters rely entirely on seeds, for which they seem well equipped, producing many more seedlings. One result of these divergent disturbance responses would be that selection on nonsprouters would be more frequent and intense (hard selection) than on sprouters (soft selection). Another would be that nonsprouters should speciate more rapidly, with shorter generation times and nonoverlapping generations. The large numbers of species in Ceanothus and Arctostaphylos was no coincidence but could be explained by their loss of sprouting from sprouting ancestors.

These ideas-that sprouters are good at persisting but carry a cost of low seed output, that selection is stronger on nonsprouters, that sprouting is the ancestral condition, and that loss of sprouting leads to high speciation rates-have spawned much of the subsequent literature on sprouters and "seeders" in Mediterranean-type ecosystems. Keeley and colleagues (Keeley 1977a, 1977b; Keeley and Keeley 1977; Keeley and Zedler 1978) were the first to explore life history trade-offs between sprouter and nonsprouter species, quantifying allocation patterns, demographic differences, biogeographic patterns, and selection regimes for sprouter/nonsprouter pairs of Ceanothus and Arctostaphylos species. Most subsequent studies in fireprone shrublands have followed their lead in exploring life history trade-offs. There are far fewer studies exploring the macroevolutionary hypotheses of Wells (1969). However, the hypotheses have been influential in framing ideas on evolutionary trends and speciation rates in disturbance-prone shrubby floras. For example, Cowling (1987), Cowling and Lamont (1998), and Wisheu et al. (2000) have argued that the exceptional species richness of Australian and South African fire-prone shrublands results partly from high speciation rates associated with short generation times of nonsprouters.

\section{Selection Regimes and the Distribution of Sprouting}

Survival to maturity. Here we consider which component of the disturbance regimes (frequency, intensity, and variabil-

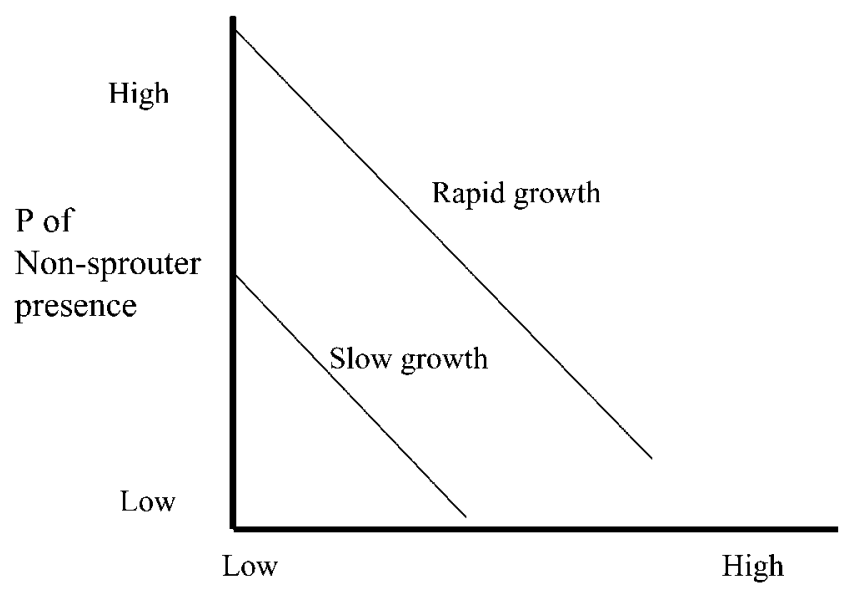

Frequency of severe disturbance

Fig. 1 Selection regimes favoring the evolution of nonsprouting. As the frequency of severe disturbance increases, the probability of a nonsprouter reaching maturity declines. If growth rates are slow because of low site productivity or plant functional traits, sprouters would be favored over a wider range of disturbance regimes. Bellingham and Sparrow (2000) suggest that nonsprouters would increase again with very high disturbance, but this is improbable for woody plants.

ity) and which life history attribute (e.g., seedling survival) best explain distribution patterns of sprouters. Selection for sprouting as a means of persistence is thought to be strongly linked to the frequency, severity, and predictability of disturbance and how they interact with regrowth rates. Nonsprouters can only survive where disturbances are rare enough, mild enough, or predictable enough to allow them to reach maturity before plants are killed. For woody plants, sprouters should increase with increasing frequency of disturbance (Keeley 1977a; Bellingham and Sparrow 2000; Bond and Midgley 2001). Since growth rates to maturity are influenced by site productivity, sprouters are likely to be more frequent in unproductive than productive sites, given similar disturbance regimes (fig. 1; Bellingham and Sparrow 2000). Growth rates to maturity also depend on intrinsic plant properties (rather than site properties), including maximum plant size, rates of carbon gain (correlated with SLA), and wood density. For a given disturbance regime and site productivity, plants with slow growth rates to maturity are therefore more likely to be sprouters than nonsprouters (fig. 1).

The disturbance regime (intensity, frequency, predictability) remains insufficiently documented for most woody ecosystems to determine which is the crucial disturbance attribute and which life history attribute is most critical. However, the frequency of nonsprouters has been shown to increase on habitat islands where fires are less frequent (fewer lightning strikes) than in large extensive areas (Bond et al. 1988; Clarke 2002). The relative cover of nonsprouters in California is negatively correlated with the frequency of lightning fires with highest cover at lower elevations (Keeley 1977a). Clarke (2002; Clarke and Knox 2002) studied sprouting behavior in adjacent vegetation on rocky outcrops and sclerophyll forests in mesic and semiarid conditions in eastern Australia. The outcrops have a 
lower fire frequency and higher proportions of nonsprouters than the adjacent forests. The pattern was found across many genera and in several different families, suggesting strong selection for nonsprouting life histories where fires are infrequent (Clarke 2002).

Keeley and Zedler (1998) have provided perhaps the most comprehensive analysis of how life history traits of trees vary in relation to disturbance regimes and site productivity. They show that several traits in conifers, including sprouting, vary in predictable ways with fire regime and productivity. Sprouting of adult trees in the genus Pinus is restricted to sites with relatively frequent, predictable, crown-fire regimes. Nonsprouters occur where crown fires are less frequent (with fire return intervals in the order of $10^{2}$ and $10^{3}$ years). Where the fire regime is one of low-intensity surface fires, there appears to be no selection for sprouting. A multivariate analysis of life history traits showed that sprouting of adult pines was correlated with short stature and serotiny (Keeley and Zedler 1998). The important conclusions from this study are that sprouting is associated with a particular fire regime, rather than fire per se, and that the severity of the disturbance, not just its frequency, influences trait distribution.

There are a few observations in the forestry literature that sprouters are also more common in frequently disturbed sites and those of lower productivity (Bellingham and Sparrow 2000; Del Tredici 2001; Itoh et al. 2002), but information is still scanty. Disturbance regimes are often heavily modified by human activity, and past regimes are difficult to reconstruct in woody ecosystems because of long disturbance intervals.

Ontogenetic responses. Divergence in adult and juvenile sprouting behavior would be expected where disturbances kill juvenile stems but not adults. In savannas, for example, frequent grass-fueled fires kill stems up to a height of ca. $3 \mathrm{~m}$ but cause little damage to stems above this "escape" height (Trollope 1984; Williams et al. 1999). Sprouting should be ubiquitous for plants below escape height, but trees that grow taller can afford to diverge in sprouting behavior. Sprouting is probably ubiquitous in woody plants caught in the flame zone of grass-fueled fires in savannas (e.g., Rutherford 1981; Hoffman 1998), but taller adults vary in sprouting behavior with as yet poorly known life history consequences. Sizerelated differences in the disturbance regime (browsing pressure, branch and tree-fall damage) might also account for ubiquitous sprouting of saplings in angiosperm trees of deciduous forests but more varied sprouting behavior of adults of different tree species (Del Tredici 2001).

The storage effect. Sprouting may also be selected where recruitment events are rare and episodic. Populations of sprouters can "store" successful recruitment events (Warner and Chesson 1985) because established plants persist from one rare recruitment event to the next (Enright and Lamont 1992; Higgins et al. 2000). The storage effect has been suggested as an important selective pressure for sprouting in fire-prone systems subject to frequent drought. Where seedlings after a burn face a high probability of drought death, sprouting would be less risky than nonsprouting (Enright and Lamont 1992). Ojeda (1998) noted that the frequency of sprouters in the genus Erica in the Cape region of South Africa increased in regions with high drought risk. Fire regimes along the geographic gradient are similar in frequency and intensity so that the storage effect is a more likely explanation of the biogeographic pattern. Some Erica species vary in sprouting behavior, and the sprouting forms were more common than the nonsprouters in droughtaffected habitats. Schutte et al. (1996) also noted that nonsprouting legumes in the Cape fynbos were more common in mesic sites or along valleys and stream banks than in drier sites. However, the reverse pattern seems to occur in Californian chaparral, where nonsprouters are more common in drier sites (Keeley 1977a; Meentemeyer and Moody 2002). Resolving these conflicting patterns will be difficult for woody plants because the storage effect operates over long time spans, and so does the disturbance regime.

\section{Sprouting and Life History Correlates}

\section{Sprouting and Recruitment Benefits}

Given the benefits of greater persistence of sprouters, it is puzzling that many species are nonsprouters, especially in firedependent shrublands (Midgley 1996). Two sets of demographic hypotheses have been proposed to explain the prevalence and frequent dominance of nonsprouters: recruitment advantage and competitive advantage. Keeley and Zedler (1978) argued that allocation costs of sprouting (such as starch to roots) would result in reduced allocation to reproductive effort. Nonsprouters are better placed to colonize gaps that might appear between sprouters simply because they may produce greater seed numbers. The trade-off between sprouting and reproductive effort could mean that nonsprouters have greater numbers of seeds reaching the gap. Early allocation by seedlings to storage reserves is another cost to sprouters. Nonsprouter seedlings can allocate resources to immediate height growth rather than storage for future survival. They should therefore have higher growth rates, lower seedling mortality, and faster maturation than sprouters.

Many studies, mostly in fire-prone ecosystems, have explored these trade-offs, usually in congeneric pairs of sprouters and nonsprouters. In general, nonsprouters produce more seeds than congeneric sprouters growing in the same site (Lamont 1985; Keeley 1986; Bond and van Wilgen 1996; Verdu 2000; Bond and Midgley 2001). Seedling growth and survival is also usually greater in nonsprouters than sprouters (Keeley 1977b; Thomas and Davis 1989; Pate et al. 1990; Bell 2001). However, there are exceptions; Schwilk (2002) reported no growth differences in a comparison of intraspecific variants of sprouting and nonsprouting forms of Ceanothus tomentosus. The juvenile period, for the few species that have been studied, is much longer in sprouters than nonsprouters (Hansen et al. 1991; Le Maitre 1992; Schwilk 2002).

There are far fewer studies of demographic trade-offs in ecosystems where fire is not an important disturbance. However, the persistence/colonization trade-off has been observed for tropical forests recovering from hurricane damage (Bellingham et al. 1994) and in South African forests (Kruger et al. 1997). Low levels of seedling recruitment are also a feature of some particularly persistent sprouting trees in temperate deciduous forests (Rackham 1986). A pattern of slow seedling growth rates in sprouters with large belowground allocation to root reserves seems quite general (Chidumayo 1992; McPherson and Williams 1998). However, we know of no studies 
comparing recruitment success in paired species that differ in adult sprouting behavior such as, for example, nonsprouting versus root-suckering Quercus species.

\section{Trade-off Mechanisms}

Allocation. Several possible mechanisms have been suggested to explain demographic trade-offs often observed in sprouter/nonsprouter comparisons. Differences in resource allocation have now been studied in many shrub species in fireprone ecosystems. In surveys of Australian and South African shrubs from fire-prone ecosystems, sprouters generally allocated more carbon to starch or other reserves in the roots (but not the shoots) than nonsprouters (Pate et al. 1990; Bell et al. 1996; Bell and Ojeda 1999). Nonsprouters had much higher shoot-to-root ratios and faster growth rates than sprouters. The most convincing evidence for a dichotomy in allocation strategies of seedlings comes from analyses of intraspecific variation for the trait. Verdaguer and Ojeda (2002) compared early growth and allocation to starch in two species of Erica from the Cape fynbos, both of which have both sprouting and nonsprouting variants. The sprouters accumulated large amounts of starch in root parenchyma, whereas nonsprouters had little or no starch. Since the plants were grown from seed under the same glasshouse conditions, the allocation differences are likely genetically determined. Schwilk (2002) has found similar patterns in a chaparral species. He grew sprouting and nonsprouting variants of C. tomentosus under common conditions and reported significantly greater total nonstructural carbohydrates in the roots of sprouters. The implication of these studies is that sprouting carries a considerable establishment cost for sprouter seedlings since they have to accumulate belowground reserves at the expense of shoot and root growth.

Differences in seedling allocation patterns to storage have also been observed in forest trees. Indeed, the only analytical model exploring optimal allocation patterns for sprouting has been developed in the context of temperate deciduous forests (Iwasa and Kubo 1997). Kobe (1997) has suggested that allocation to storage may be an effective strategy of shade tolerance because it is relatively inexpensive under low light, and it provides a buffer against stresses. Canham et al. (1999) reported increased survival of defoliated tree seedlings of four temperate deciduous tree species, with increasing allocation to nonstructural carbohydrate. However, not all sprouting trees utilize stored carbon. Sakai et al. (1997) compared allocation patterns in three tree species that sprout vigorously after damage by frequent landslides. Two of the species store large amounts of starch, but one does not. Instead, it remobilizes current photosynthate to support resprouting stems (Sakai and Sakai 1998). It is not known how common this "resource remobilization" mechanism is in trees nor how much it reduces demographic and growth rate trade-offs of recruits. At least some of the variability in trade-off patterns may result from resource remobilization versus utilization of stored reserves for subsidizing sprouting shoots.

\section{Seed Production}

Once adequate reserves have been laid down to support future sprouting, allocation of current photosynthate to stor-

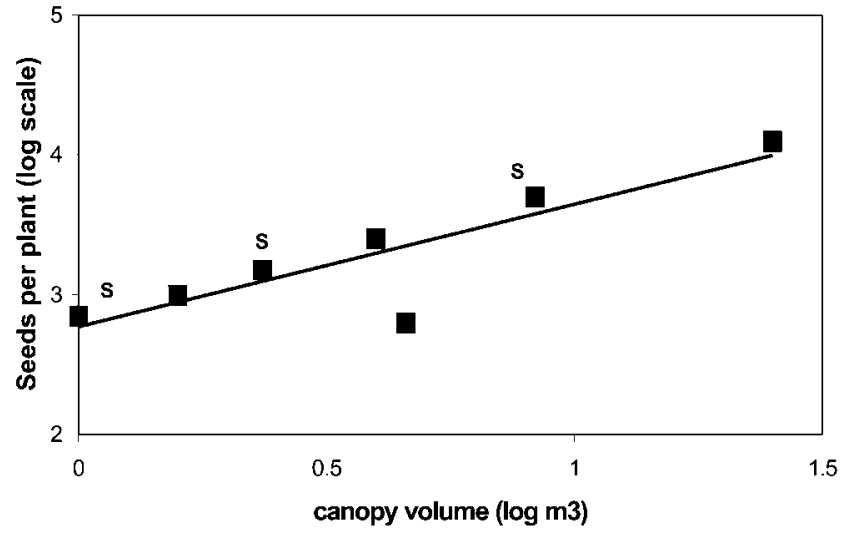

Fig. 2 Seed number versus plant size, measured as canopy volume (cubic meters) for six species of sprouting (indicated by $S$ ) and nonsprouting Leucadendron species from the Cape fynbos (W. J. Bond and J. J. Midgley, unpublished data). Comparisons of seed number of sprouters versus nonsprouters need to take size differences into account since sprouters are often smaller plants.

age should decrease. Indeed, Cruz and Moreno (2001) found no biomass trade-off between reproductive effort and starch storage in lignotubers of adult Erica australis. It is therefore surprising that seed production in adult plants is often greater in nonsprouter-sprouter comparisons. Seedbank comparisons between sprouters and nonsprouters have usually controlled for phylogeny in the sense that comparisons are typically made between intrageneric species growing in the same site. However, unlike analyses of the ecological importance of seed size (Jacobsson and Eriksson 2000), most studies have not taken into account other sources of variation such as differences in plant size or seed size between contrasted species. Especially in fire-prone ecosystems, sprouters are typically multistemmed and shorter than nonsprouters. Size differences alone might account for larger seed numbers in nonsprouters (fig. 2).

\section{Sprouting, Plant Size, and Competition}

A second important cost of sprouting, independent of allocation to storage, is reduced plant height of sprouters relative to nonsprouters. Midgley (1996) noted that nonsprouters are typically single stemmed and taller than co-occurring congeneric sprouters. He suggested that nonsprouters would gain a competitive advantage through their single-stemmed habit and greater height, overtopping multistemmed sprouters. Height differences alone might account for the frequent dominance of nonsprouters in fire-prone ecosystems. However many plants are capable of thinning sprouting stems down to a single trunk (including the tallest tree on earth, Sequoia sempervirens). Where species lack the capacity to thin out stems and remain multistemmed as adults, the height trade-off associated with sprouting may favor nonsprouters in competition for light.

\section{Reproductive Performance}

Wells (1969) argued that nonsprouters would be subjected to more frequent and intense selection than sprouters. The demographic expression of these differences might be, for 
sprouters, poorer seed production and reduced seedling vitality relative to nonsprouters. However, persistence at a site brings its own additional problems and may result in different selection pressures on sprouters, for example, for greater dispersal (away from the adult) than nonsprouters (Carpenter and Recher 1979; Keeley 1986). There have been various tests of these hypothesized secondary traits associated with sprouting (reviewed in Whelan 1995). For example, a comparison of serotiny ("closed cone behavior") in Proteaceae showed that sprouters tended to be weakly serotinous and nonsprouters strongly serotinous (Lamont et al. 1985). Since no allocation cost has yet been attributed to serotiny, these differences suggest stronger selection on maintaining larger seedbanks in nonsprouters.

There have also been suggestions that nonsprouters should evolve self-compatible breeding systems because of the premium on seed production, whereas sprouters are more likely to evolve xenogamy (Carpenter and Recher 1979; Fulton and Carpenter 1979). Xenogamy might lead to lower seed production in sprouters because of pollinator failure or incompatibility problems. However, there is no clear pattern in the few studies that explore possible correlates with sprouting and breeding systems (Lamont et al. 1998).

The question of whether selection for factors influencing seedling regeneration is weaker in sprouters or merely different from nonsprouters has been elegantly addressed by Clark (1991). He modeled optimal maturation for two co-occurring pine species, Pinus resinosa, a sprouter, and Pinus banksiana, a nonsprouter, both exposed to the same fire regime. His model tested the assumption that alternative life history strategies maximize different quantities: the number of reproductive episodes in sprouters and the probability for nonsprouters of being reproductively mature at the time of the next fire. He found a good fit between predicted and observed maturation times (55 yr for the sprouter and just $25 \mathrm{yr}$ for the nonsprouter). The implication is that secondary life history traits may diverge when plants evolve different sprouting strategies because they are exposed to different selection pressures and not because selection is weaker in sprouters.

Recently, Lamont and Wiens (2003) have proposed another consequence of sprouting related to differences in life span. Sprouter life spans, at least in fire-prone ecosystems, are thought to be 10 to 100 times longer than nonsprouters (Bond and van Wilgen 1996). Lamont and Wiens suggest that sprouters are likely to accumulate deleterious alleles from somatic mutations over their long lives (Wiens et al. 1987), whereas nonsprouters would purge them at each successive recruitment episode. They suggest that sprouters would carry a high genetic load and that this would most likely be expressed in poor fruit and seed set. As an example, they cite Banksia elegans, a rootsuckering shrub that produces nonviable pollen in some clones, rendering them barren. The genetic load hypothesis might help explain the enigmatic very low occurrence or complete absence of seed set in some vigorously sprouting lignotuberous species (such as Retzia in Cape fynbos), which show no other obvious reproductive problems.

\section{Summary of Trade-Offs}

Among the various trade-offs suggested for sprouters versus nonsprouters, the clearest difference seems to be in relative growth rate of seedlings. Growth rate differences also make sense because of the divergent allocation requirements of sprouters and nonsprouters. However, these establishment trade-offs are likely to be restricted to fire-prone ecosystems. In temperate and tropical forests and in savannas, most, if not all, woody angiosperms resprout as seedlings and saplings. All should face similar trade-offs between allocation to aboveground growth versus belowground storage at the seedling stage. Persistence versus colonization trade-offs between species that differ in adult sprouting strategy cannot easily be explained by allocation differences at juvenile stages.

\section{Sprouting and Macroevolution}

Very few studies have explored the longer term evolutionary implications of sprouting suggested by Wells (1969). Is sprouting an ancestral trait in angiosperms? Is sprouting behavior an evolutionarily conservative trait? Are there phylogenetic patterns in the distribution of sprouting among major clades? And, as Wells (1969) suggested, does loss of sprouting promote speciation?

Tiffney and Niklas (1986) analyzed trends of clonal growth forms as revealed in the fossil record. Their clonal types include rhizomes, basal suckering (equivalent to crown sprouting), root suckering, and layering. All early land plants spread clonally by rhizomes. The frequency of clonal (sprouting) forms declined with the appearance of aclonal trees, increasing again only with the appearance of angiosperm herbaceous forms, including grasses, in the Tertiary period. The trade-off between height and sprouting seen in many contemporary floras (Midgley 1996) seems to have long antecedents.

Clearly, the nuances of sprouting behavior in trees (Del Tredici 2001) are unlikely to be preserved in the fossil record. Unfortunately, phylogenetic patterns in contemporary floras have been little explored. The conifers form an interesting group worthy of further phylogenetic and ecological analysis of sprouting behavior. Sprouting is generally rare in conifers, with root collar sprouting apparently restricted to Taxodiaceae and Taxaceae in the northern hemisphere (Del Tredici 2001). In the southern hemisphere, several conifers in south temperate forests sprout, including species of Athrotaxis, a genus in the Taxodiacae in Tasmania, which produce root suckers, and several members of the Podocarpaceae (e.g., Lagarostrobus, Phyllocladus; Gibson et al. 1995). These forests seldom or never burn. In marked contrast, sprouting also occurs as a probable fire adaptation in several species of Pinus occurring in shrublands or grasslands subject to frequent crown fires (Keeley and Zedler 1998). Sprouting ability in these species is derived secondarily from buds above the root collar. In the southern hemisphere, a similar group of fire-adapted sprouting conifers in the Cupressaceae and Podocarpaceae occur in comparable fire regimes (Midgley et al. 1995; Keeley et al. 1998). Thus, sprouting appears to have evolved under quite different selective regimes in conifers: in frequently disturbed crown fire regimes and in forests where fire is not an important factor. The latter appears to be of more ancient origin, but the costs and benefits of sprouting in these systems has yet to be explored.

We know of no formal analysis of variation in sprouting among angiosperm families, though it would be interesting to 


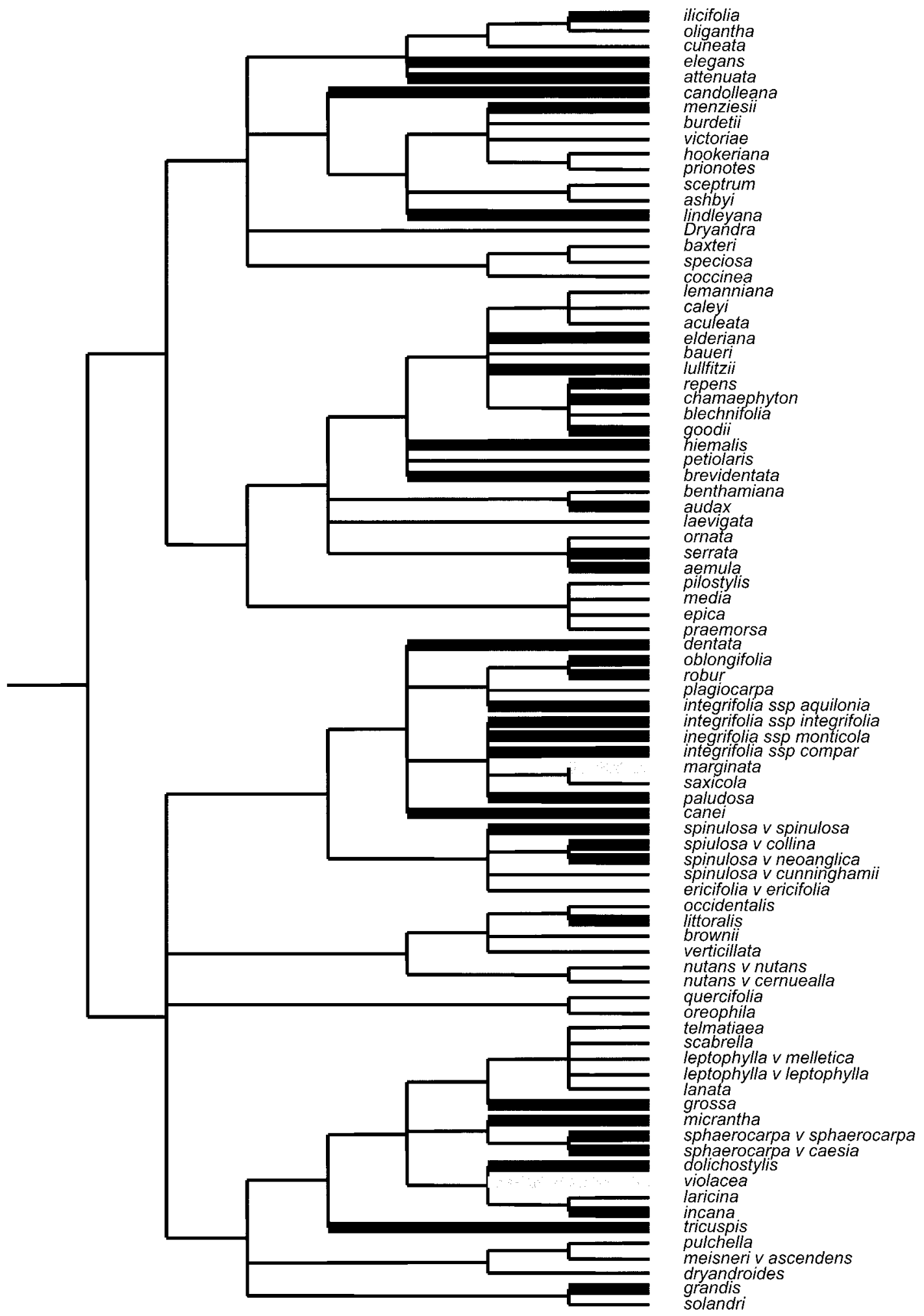

Fig. 3 Phylogeny of Banksia (Proteaceae) based on chloroplast DNA (ex Mast and Givnish 2002) showing distribution of sprouting (black bands) and nonsprouting life history strategies. Taxa with gray bands have both sprouting and nonsprouting populations. Dryandra is included in the paraphyletic Banksia. 


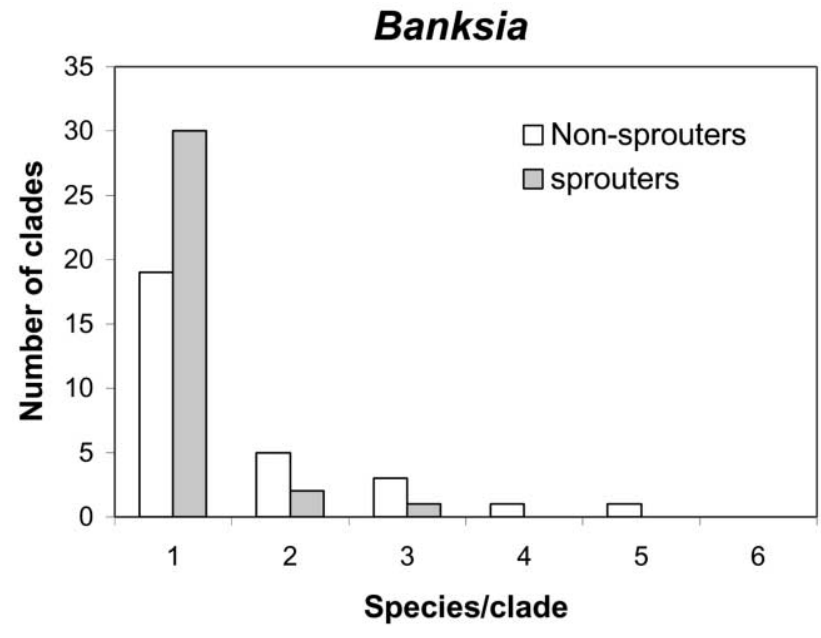

Fig. 4 Diversification of sprouters versus nonsprouters in Banksia (Proteaceae) in Australia, based on a molecular phylogeny (Mast and Givnish 2002). The number of terminal taxa in monophyletic clades is significantly greater in nonsprouters than sprouters (Mann-Whitney $U$-test, adjusted $Z$ value $2.48, P<0.05$ ).

determine whether loss of sprouting is more prevalent in some families than others.

\section{Phylogenetic Analysis}

The increasing availability of phylogenies for genera with well-known sprouting behavior creates new opportunities for testing Wells's evolutionary hypotheses. A molecular phylogeny for Ceanothus, the large chaparral genus with nearly $80 \%$ of its members nonsprouters, has been published recently (Hardig et al. 2000). The basal division between the subgenus $\mathrm{Ce}$ rastes (all nonsprouters) and the subgenus Ceanothus (mostly sprouters with some nonsprouters) is very well supported. This indicates an early separation of the genus into sprouting and nonsprouting clades, with several more recent shifts to nonsprouting in subgenus Ceanothus. Unfortunately, clades within the subgenera are poorly resolved. A new molecular phylogeny of Rhamnaceae can help resolve the question of whether sprouting is ancestral or derived in Ceanothus (Richardson et al. 2000) once sprouting behavior has been characterized for related genera. At least one of these genera, Phylica, from Africa and nearby islands, has both sprouting and nonsprouting species (F. Weitz, personal communication, 2003) and, like Ceanothus, has speciated extensively (>100 species) in Cape fynbos.

Molecular phylogenies have recently become available for two large genera in the Proteaceae, Banksia in Australia and Protea in Africa. Both genera occur in fire-prone shrublands; sprouting behavior of the taxa is well known (George 1981 for Banksia; Rebelo 1996 for Protea), and phylogenies are available for both (Thiele and Ladiges 1996; Mast 1998; Reeves 2001 for Protea; Mast and Givnish 2002 for Banksia).

\section{Banksia}

Is sprouting ancestral, and is the loss of sprouting a derived trait, as suggested by Wells (1969)? In their morphologically based phylogeny of Banksia, Thiele and Ladiges (1996) included the presence or absence of a lignotuber as one of the characters. A molecular phylogeny, based on chloroplast DNA and nuclear ribosomal DNA sequence data of 18 species of Banksia and five of Dryandra, is congruent with the morphological cladistic analysis (Mast 1998), except that Banksia appears to be paraphyletic and includes the monophyletic Dryandra. A more complete molecular phylogeny of Banksia has recently been published (Mast and Givnish 2002) and includes several species of Dryandra. We scored terminal taxa on their phylogeny for sprouting behavior (George 1981; Thiele and Ladiges 1996). The phylogenetic analysis of Banksia (excluding Dryandra) shows that sprouting is a highly homoplasious character (fig. 3). Many (eight) terminal sister taxa in the phylogeny have contrasting sprouting modes. Some species contain both sprouting and nonsprouting populations. For example, Banksia violacea, a member of a nonsprouting clade in the series Abietinae, has some sprouting populations with lignotubers. In short, there is very little phylogenetic pattern in the appearance of sprouting or nonsprouting in Banksia. Clearly, sprouting behavior is a poorly conserved trait in this genus, and the high levels of homoplasy indicate that fire life history is an evolutionarily labile trait.

We tested the hypothesis that nonsprouting leads to greater speciation by comparing the number of species in clades with uniform fire life histories. If nonsprouting promotes speciation, than we would expect that clades uniform for this trait should have more species than sprouting clades. Since many of the clades are poorly resolved and there are many polytomies, there are many single-species clades from this Banksia phylogeny. The frequency distribution of species/clade for sprouters versus nonsprouters is shown in figure 4 (terminal taxa with mixed strategies are counted as nonsprouters). Nonsprout-

ers have significantly more species per clade than sprouters. Among sprouters, 30 clades have only a single species, and only three have more than one species. Nonsprouters have fewer (19) monospecific clades and 10 with two or more species (up to a maximum of five). This analysis, therefore, finds weak support for the hypothesis that loss of sprouting is associated with greater speciation. About half the genus consists of sprouting species. However, the most striking feature of the phylogeny is the fact that both life history types occur in many polytomies, indicating rapid evolutionary divergence of both sprouters and nonsprouters. The problem of whether sprouting is ancestral in the genus requires more analysis. However, the answer is of little relevance to Wells's argument, given the homoplasious nature of the trait.

\section{Protea}

Protea has evolved convergent features to Banksia in the fynbos vegetation of the Cape region of South Africa (Cowling and Lamont 1998). It differs in the much greater prevalence of nonsprouting species ( $>70 \%$ of Cape species). However, Protea also extends to summer rainfall areas of South Africa where several species form the tree component of mesic, frequently burnt savannas. All 16 summer rainfall taxa sprout. Reeves (2001) has produced a molecular phylogeny of the genus. We used the same procedure as for Banksia to test 
whether nonsprouter clades are richer in species than sprouters (fig. 5). As in Banksia, the results show that nonsprouting clades have significantly more species than sprouters, consistent with Wells's hypothesis. However, it is again striking that sprouting is a highly labile trait with numerous monophyletic sprouting clades, suggesting that sprouting has evolved independently many times. The high origination rate of sprouting is only revealed in phylogenetic analysis and not in the overall frequency of sprouters in the genus.

The above analysis is flawed, however, by not taking time of divergence into account (Magallon and Sanderson 2001). We do not have enough sister clades to make statistically rigorous comparisons of species richness versus life history. Reeves used her phylogeny to test relative rates of speciation based on number of base pair substitutions (Reeves 2001). She analyzed sprouting and nonsprouting patterns to test whether speciation rates are greater in nonsprouting taxa. All monophyletic groups made up exclusively of nonsprouters or sprouting species were identified from the tree. Diversification rate was estimated for each of these clades based on sequence differences. Average diversification rates were then calculated for nonsprouters and sprouters, including all lineages for which the diversification rate was zero (i.e., clade of one species). For comparison, diversification rate was also estimated for the summer rainfall sprouting clade (which includes tropical and South African representatives).

As in Banksia, Reeves (2001) noted that switches between traits have occurred several times within the genus. Estimated diversification rates for eight exclusively nonsprouting and three sprouting clades are listed in table 2 . The values estimated for nonsprouters are all higher than those estimated for sprouting clades. Including all the lineages for which diversification rate was zero, the overall speciation rate for nonsprouters was more than three times greater than for sprouters. The difference in mean speciation rate is statistically significant. In Protea, increased diversification rate is certainly associated with "reseeding" lineages in Cape taxa. However, estimated diversification rate for summer rainfall lineages, all of which are sprouters and which are monophyletic, were higher than all but one of the estimates for nonsprouting lineages in the Cape. Reeves

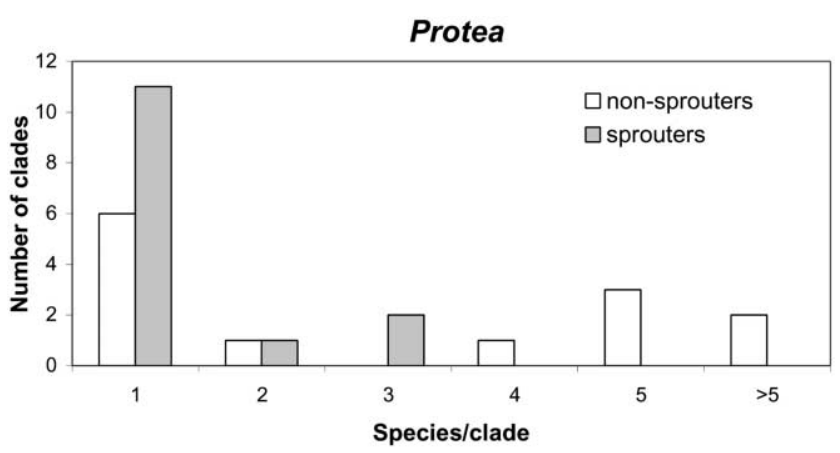

Fig. 5 Diversification of sprouters versus nonsprouters in Protea (Proteaceae) in the Cape region of South Africa. The number of terminal taxa in monospecific clades is significantly greater in nonsprouters than sprouters (Mann-Whitney $U$-test, adjusted $Z$ value 2.06, $P<0.05)$. The analysis is based on a molecular phylogeny by Reeves (2001).

\section{Table 2}

Number of Species and Relative Diversification Rates (DR) of Sprouting and Nonsprouting Protea Clades

\begin{tabular}{ccccc}
\hline \multicolumn{2}{c}{ Nonsprouters } & & & \multicolumn{2}{c}{ Sprouters } \\
\cline { 1 - 2 } Number of taxa & DR & & Number of taxa & DR \\
\hline 2 & 0.0427 & 3 & 0.0278 \\
5 & 0.0463 & & 0.0278 \\
10 & 0.0467 & & 0.0285 \\
5 & 0.0556 & & Monospecific clades: & \\
8 & 0.0452 & & 6 & .0667 \\
4 & 0.0355 & & Summer rainfall clade: \\
5 & 0.0648 & & 16 & \\
2 & 0.0694 & & \\
Monospecific clades: & & & & \\
6 & & &
\end{tabular}

Note. Rates estimated from a molecular phylogeny of Protea (Reeves 2001).

(2001) concludes that sprouting per se does not inhibit speciation. She suggests that the real problem must be high extinction rates for sprouters in the winter rainfall-shrubland fire regimes. Sprouting appears to be an evolutionary dead end for fynbos Protea but not, apparently, for southwestern Australian Banksia, where sprouters are numerous. Fires are more frequent in Australian kwongan and may have selected for more sprouter species, consistent with the ideas that frequent disturbance favors sprouters (Cowling and Lamont 1998). Lower fire frequencies in fynbos not only favor persistence of nonsprouters but may also account for higher extinction rates of sprouters since there is more time for nonsprouters to overtop and shade out sprouting congeners (Midgley 1996). In summer rainfall vegetation, sprouting proteas usually form trees in grasslands or low shrublands where fires are too frequent for taller nonsprouting competitors.

\section{Cliffortia}

Speciation patterns in relation to sprouting have also recently been explored for the large genus Cliffortia (Rosaceae), mostly shrubby species common in Cape fynbos (Whitehouse 2003). Cliffortia differs from many fynbos genera in having a number of root-suckering species as well as root crown sprouters and nonsprouters. Of the 113 Cape species for which sprouting strategy is known (out of 131 species), $38.9 \%$ are clonal (root suckering), $10.8 \%$ are root crown sprouters, $47.8 \%$ are nonsprouters, and $2.7 \%$ have mixed strategies. Whitehouse noted that fire-survival strategy was the most homoplasious of all the morphological characters used in his analysis. According to his phylogeny, nonsprouters are derived only from clonal sprouters and not from crown sprouters (table

Table 3

Number of Shifts between Different Life Histories in Cliffortia L. (Rosaceae) (ex Whitehouse 2003)

\begin{tabular}{lcc}
\hline Sprouting mode & Changes & Reversals \\
\hline Nonsprouter to crown sprouter & 7 & 0 \\
Nonsprouter to clonal sprouter & 12 & 8 \\
Clonal sprouter to crown sprouter & 1 & 0 \\
\hline
\end{tabular}


3). Nonsprouting ancestors have generated both clonal and crown sprouters repeatedly (table 3 ), a pattern completely contradicting Wells's hypothesis for the directionality of evolution in chaparral Ceanothus and Arctostaphylos life histories. As in Banksia and Protea, fire survival strategy in Cliffortia is a highly labile evolutionary trait.

These first attempts at exploring the evolution of sprouting using phylogenies are still very preliminary. However, they are all similar in indicating that, at least as a fire survival strategy, sprouting is not a conserved trait. H. P. Linder (personal communication, 2001) has found similar homoplasies as regards sprouting in a phylogeny of Cape Restionaceae. Aberrant sprouting variants of nonsprouting species have also been found in Ericaceae (Ojeda 1998) and Fabaceae in the Cape (Schutte et al. 1995). It would seem, at least for these examples, that sprouters have evolved from nonsprouters many times. Longer life spans do not seem to be an obstacle to generating novel genomes. Perhaps, as suggested by Reeves (2001), we should be exploring rates of extinction rather than speciation to account for different proportions of the life history strategies in fire-dependent shrublands. Certainly, these initial results are at variance with long-held generalizations on the evolutionary consequences of fire survival strategies stemming from Wells (1969). Hypotheses for the high species richness of floras with many nonsprouters (Cowling 1987; Wisheu et al. 2000), based on the assumption of higher speciation rates, clearly need to be revisited as more data accumulates.

The idea that sprouting slows speciation has also been challenged by Lamont and Wiens (2003). They note that many species-rich genera in fire-prone ecosystems contain numerous sprouting species. Sprouters make up $49 \%-75 \%$ of local floras in southwest Australia (Bell 2001) and comprise just over half of a sample of 4418 species of the Cape flora (Le Maitre and Midgley 1992). They suggest that higher genetic load in sprouters, accumulated by somatic mutation over their long lives, not only will accumulate deleterious mutations but may also be a source of genetic novelty. They suggest that "coupling strong xenogamy-longevity with frequent fire maximizes opportunities for production of novel offspring via the high mutational load of the parents" (Lamont and Wiens 2003). This mechanism might explain why speciation rates among sprouters can keep pace with nonsprouters.

\section{Conclusion}

Variability in sprouting is widespread in woody taxa. Sprouting behavior is an ecologically important trait for understanding vegetation change but is still poorly described in many biomes. Though many studies in fire-prone ecosystems and some in forests indicate a persistence/colonization tradeoff, the generality of these patterns needs much further testing for a much wider range of species and ecosystems. The tools to explore evolutionary patterns and processes linked to sprouting have only recently become available with the development of phylogenetic methods and the growing availability of molecular phylogenies. Initial results indicate that sprouting is not a conserved trait and that it is highly labile, at least for three large fire-adapted genera. Reversals are common, and there is little support for the suggestion that sprouting is ancestral, or a conserved trait, in these taxa. Though there is weak support for the idea that speciation rates are higher among nonsprouters, it is too weak to use as an argument that selection for nonsprouting life histories has been a major factor in speciation in the rich floras of the Cape, southwest Australia, and other regions where nonsprouters are common. Instead, it seems that diversification is generally high in these areas for both life history types. In conclusion, it appears that the hypotheses of Wells (1969) are both incorrect in pattern (speciation rates) and process (allocation). Biogeographic patterns suggest that strong ecological factors explain abundance and numbers of species of sprouters.

\section{Acknowledgments}

We thank Gail Reeves, Austin Mast, and Chris Whitehouse for making their phylogenetic analyses available to us. C. J. Fotheringham, Terry Hedderson, Steve Hopper, Byron Lamont, Peter Linder, Fernando Ojeda, and Tony Verboom all provided generous assistance and expertise. David Ackerly and two anonymous reviewers made many helpful comments on the manuscript.

\section{Literature Cited} $\rightarrow$ Bell DT 2001 Ecological response syndromes in the flora of south-
western Australia: fire resprouters versus reseeders. Bot Rev 67: 417-440.

Bell DT, AJM Hopkins, JS Pate 1984 Fire in the kwongan. Pages 178-204 in JS Pate, JS Beard, eds. Kwongan: plant life of the sandplain. University of Western Australia Press, Nedlands.

$\rightarrow$ Bell TL, F Ojeda 1999 Underground starch storage in Erica species of the Cape Floristic Region-differences between seeders and resprouters. New Phytol 144:143-152.

$\rightarrow$ Bell TL, JS Pate, KW Dixon 1996 Relationships between fire response, morphology, root anatomy and starch distribution in southwest Australian Epacridaceae. Ann Bot 77:357-364.

$\rightarrow$ Bellingham PJ, AD Sparrow 2000 Resprouting as a life history strategy in woody plant communities. Oikos 89:409-416.

$\rightarrow$ Bellingham PJ, EVJ Tanner, JR Healy 1994 Sprouting of trees in Jamaican montane forests after a hurricane. J Ecol 82:747-758.
Bond WJ, JM Midgley 2001 The persistence niche: ecology of sprouting in woody plants. Trends Ecol Evol 16:45-51.

$\rightarrow$ Bond WJ, JJ Midgley, J Vlok 1988 When is an island not an island? insular effects and their causes in Fynbos shrublands. Oecologia 77: 515-521.

Bond WJ, BW Van Wilgen 1996 Fire and plants. Chapman \& Hall, London. 263 pp.

$\rightarrow$ Burrows GE 2002 Epicormic strand structure in Angophora, Eucalyptus and Lophostemon (Myrtaceae)-implications for fire resistance and recovery. New Phytol 153:111-131.

$\rightarrow$ Canadell J, L Lopez-Soria 1998 Lignotuber reserves support regrowth following clipping of two Mediterranean shrubs. Funct Ecol 12: 31-38.

$\rightarrow$ Canham CD, RK Kobe, EF Latty, RL Chazdon 1999 Interspecific and intraspecific variation in tree seedling survival: effects of allocation to roots versus carbohydrate reserves. Oecologia 121:1-11. 
$\rightarrow$ Carpenter FL, HF Recher 1979 Pollination, reproduction, and fire. Am Nat 113:871-879.

$\rightarrow$ Chidumayo EN 1992 Seedling ecology of two miombo woodland trees. Vegetatio 103:51-58.

$\rightarrow$ Clark JS 1991 Disturbance and tree life history on the shifting mosaic landscape. Ecology 72:1102-1118.

$\rightarrow$ Clarke PJ 2002 Habitat insularity and fire response traits: evidence from a sclerophyll archipelago. Oecologia 132:582-591.

$\rightarrow$ Clarke PJ, KJE Knox 2002 Post-fire response of shrubs in the tablelands of eastern Australia: do existing models explain habitat differences? Aust J Bot 50:53-62.

Cowling RM 1987 Fire and its role in coexistence and speciation in Gondwanan shrublands. S Afr J Sci 83:106-112.

$\rightarrow$ Cowling RM, BB Lamont 1998 On the nature of Gondwanan species flocks: diversity of Proteaceae in Mediterranean southwestern Australia and South Africa. Aust J Bot 46:335-355.

$\rightarrow$ Cruz A, JM Moreno 2001 No allocation trade-offs between flowering and sprouting in the lignotuberous, Mediterranean shrub Erica australis. Acta Oecol 22:121-127.

$\rightarrow$ Del Tredici P 2001 Sprouting in temperate trees: a morphological and ecological review. Bot Rev 67:121-140.

Enright NJ, BB Lamont 1992 Recruitment variability in the resprouting shrub Banksia attenuata and nonsprouting congeners in the northern sandplain heaths of southwestern Australia. Acta Oecol 13:727-741.

$\rightarrow$ Feild TS, NC Arens, TE Dawson 2003 The ancestral ecology of angiosperms: emerging perspectives from extant basal lineages. Int J Plant Sci 164(suppl):S129-S142.

$\rightarrow$ Fulton RE, FL Carpenter 1979 Pollination, reproduction and fire in California Arctostaphylos. Oecologia 38:147-157.

George AS 1981 The genus Banksia L.f. (Proteaceae). Nuytsia 3: 239-473.

Gibson N, PCJ Barker, PJ Cullen, A Shapcott 1995 Conifers of Southern Australia. Pages 223-251 in NJ Enright, RS Hill, eds. Ecology of the Southern conifers. Melbourne University Press, Melbourne.

Grime JP 1979 Plant strategies and vegetation processes. Wiley, Chichester.

$\rightarrow$ Grime JP, K Thompson, R Hunt, JG Hodgson, JHC Cornelissen, IH Rorison, GAF Hendry, et al 1997 Integrated screening validates primary axes of specialisation in plants. Oikos 79:259-281.

$\rightarrow$ Grubb P 1977 The maintenance of species richness in plant communities: the importance of the regeneration niche. Biol Rev 52: 107-145.

Hansen A, JS Pate, AP Hansen 1991 Growth and reproductive performance of a seeder and a resprouter species of Bossiaea as a function of plant age after fire. Ann Bot 67:497-509.

$\rightarrow$ Hardig TM, PS Soltis, DE Soltis 2000 Diversification of the North American shrub genus Ceanothus (Rhamnaceae): conflicting phylogenies from nuclear ribosomal DNA and chloroplast DNA. Am J Bot 87:108-123.

$\rightarrow$ Higgins SI, STA Pickett, WJ Bond 2000 Predicting extinction risks for plants: environmental stochasticity can save declining populations. Trends Ecol Evol 15:516-520.

$\rightarrow$ Hodgkinson KC 1998 Sprouting success of shrubs after fire: heightdependent relationships for different strategies. Oecologia 115: 64-72.

$\rightarrow$ Hoffman WA 1998 Postburn reproduction of woody plants in a neotropical savanna: the relative importance of sexual and vegetative reproduction. J Appl Ecol 35:422-433.

$\rightarrow$ Itoh A, T Yamakura, M Kanzaki, T Ohkubo, PA Palmiotto, JV LaFrankie, JJ Kendawang, HS Lee 2002 Rooting ability of cuttings relates to phylogeny, habitat preference, and growth characteristics of tropical rainforest trees. For Ecol Manage 168:275-287.

$\rightarrow$ Iwasa Y, T Kubo 1997 Optimal size of storage for recovery after unpredictable disturbances. Evol Ecol 11:41-65.

$\rightarrow$ Jacobsson A, O Eriksson 2000 A comparative study of seed number, seed size, seedling size, and recruitment in grassland plants. Oikos $88: 494-502$.

$\rightarrow$ James S 1984 Lignotubers and burls-their structure, function, and ecological significance in Mediterranean ecosystems. Bot Rev 50: 225-266.

Keeley JE 1977 a Fire-dependent reproductive strategies in Arctostaphylos and Ceanothus. Pages 391-396 in HA Mooney, CE Conrad, eds. Proceedings of the Symposium on Environmental Consequences of Fire and Fuel Management in Mediterranean Ecosystems. USDA Forest Service General Technical Report WO-3.

$\rightarrow-1977 b$ Seed production, seed populations in soil, and seedling production after fire for two congeneric pairs of sprouting and nonsprouting chaparral shrubs. Ecology 58:820-829.

1986 Resilience of Mediterranean shrub communities to fires. Pages 95-112 in B Dell, AJ Hopkins, BB Lamont, eds. Resilience in Mediterranean-type ecosystems. Junk, The Hague.

$\rightarrow$ Keeley JE, MB Keeley, WJ Bond 1998 Stem demography and postfire recruitment of a resprouting serotinous conifer. J Veg Sci 10:69-76.

$\rightarrow$ Keeley JE, SC Keeley 1977 Energy allocation patterns of a sprouting and a nonsprouting species of Arctostaphylos in the California chaparral. Am Midl Nat 98:1-10.

$\rightarrow$ Keeley JE, PH Zedler 1978 Reproduction of chaparral shrubs after fire: a comparison of sprouting and seeding strategies. Am Midl Nat 99:142-161.

1998 Evolution of life histories in Pinus. Pages 219-249 in DM Richardson, ed. Ecology and biogeography of Pinus. Cambridge University Press, Cambridge.

$\rightarrow$ Kobe RK 1997 Carbohydrate allocation to storage as a basis of interspecific variation in sapling survivorship and growth. Oikos 80: 226-233.

$\rightarrow$ Kruger LM, JJ Midgley, RM Cowling 1997 Resprouters vs. reseeders in South African forest trees: a model based on forest canopy height. Funct Ecol 11:101-105.

$\rightarrow$ Lamont B 1985 The comparative reproductive biology of three Leucospermum species (Proteaceae) in relation to fire responses and breeding system. Aust J Bot 33:139-145.

Lamont BB, BC Collins, RM Cowling 1985 Reproductive biology of the Proteaceae in Australia and South Africa. Proc Ecol Soc Aust 14:213-224.

$\rightarrow$ Lamont BB, JM Olesen, P Briffa 1998 Seed production, pollinator attractants, and breeding systems of two species pairs in relation to fire response-are there reproductive syndromes? Aust J Bot 46: 377-385.

Lamont BB, DL Wiens 2003 Is seed set always low among species that resprout after fire, and why? a meta-analysis. Evol Ecol (in press).

$\rightarrow$ Langley JA, Drake BG, Hungate BA 2002 Extensive belowground carbon storage supports roots and mycorrhizae in regenerating scrub oaks. Oecologia 131:542-548.

Le Maitre DC 1992 The relative advantages of seeding and sprouting in fire-prone environments: a comparison of life histories of Protea neriifolia and Protea nitida. Pages 123-143 in BW van Wilgen, DM Richardson, FJ Kruger, HJ van Hensbergen, eds. Fire in South African mountain fynbos. Springer, Berlin.

Le Maitre DC, JJ Midgley 1992 Plant reproductive ecology. Pages 135-174 in RM Cowling, ed. The ecology of fynbos: nutrients, fire, and diversity. Oxford University Press, Cape Town.

$\rightarrow$ Lloret F, M Verdu, N Flores-Hernandez, A Valinete-Banuet 1999 Fire and resprouting in Mediterranean ecosystems: insights from an external biogeographical region, the Mexicali shrubland. Am J Bot 86:1655-1661.

$\rightarrow$ Magallon S, MJ Sanderson 2001 Absolute diversification rates in angiosperm clades. Evolution 55:1762-1780.

$\rightarrow$ Mast ARE 1998 Molecular systematics of subtribe Banksiinae (Banksia and Dryandra; Proteaceae) based on cpDNA and nrDNA se- 
quence data: implications for taxonomy and biogeography. Aust Syst Bot 11:321-342.

$\rightarrow$ Mast ARE, TJ Givnish 2002 Historical biogeography and the origin of stomatal distributions in Banksia and Dryandra (Proteaceae) based on their cpDNA phylogeny. Am J Bot 89:1311-1323.

$\rightarrow$ McPherson K, K Williams 1998 The role of carbohydrate reserves in the growth, resilience, and persistence of cabbage palm seedlings (Sabal palmetto). Oecologia 117:460-468.

$\rightarrow$ Meentemeyer RK, A Moody 2002 Distribution of plant life history types in California chaparral: the role of topographically determined drought severity. J Veg Sci 13:67-78.

$\rightarrow$ Mesleard E, J Lepart 1989 Continuous basal sprouting from a lignotuber Arbutus unedo L. and Erica arborea L. as woody Mediterranean examples. Oecologia 80:127-131.

$\rightarrow$ Midgley JJ 1996 Why the world's vegetation is not totally dominated by resprouting plants: because resprouters are shorter than reseeders. Ecography 19: 92-95.

Midgley JJ, WJ Bond, CJ Geldenhuys 1995 The ecology of southern African conifers. Pages 64-80 in NJ Enright, RS Hill, eds. Ecology of the southern conifers. Melbourne University Press, Melbourne.

Ojeda F 1998 Biogeography of seeder and resprouter Erica species in the Cape Floristic region-where are the resprouters? Biol J Linn Soc 63:331-347.

Pate JS, RH Froend, BJ Bowen, A Hansen, J Kuo 1990 Seedling growth and storage characteristics of seeder and resprouter species of Mediterranean-type ecosystems of S.W. Australia. Ann Bot 65: 585-601.

Rackham O 1986 The history of the countryside. Dent, London.

Rebelo AS 1996 Proteas: a field guide to the proteas of Southern Africa. Fernwood, Vlaeberg, South Africa.

Reeves G 2001 Radiation and macroevolutionary ecology of the African genus Protea L. (Proteaceae). PhD thesis. Imperial College, Silwood Park, U.K.

$\rightarrow$ Reich PB, MB Walters, DS Ellsworth 1992 Leaf life span in relation to leaf, plant, and stand characteristics among diverse ecosystems. Ecol Monogr 62:365-392.

$\rightarrow$ Richardson JE, MF Fay, QCB Cronk, D Bowman, MW Chase 2000 A phylogenetic analysis of Rhamnaceae using rbcL and trnL-F plastid DNA sequences. Am J Bot 87:1309-1324.

Rutherford MC 1981 Survival, regeneration, and leaf biomass changes in woody plants following spring burns in Burkea africana-Ochna pulchra savanna. Bothalia 13:531-552.

$\rightarrow$ Sakai A, S Sakai 1998 A test for the resource remobilization hypothesis: tree sprouting using carbohydrates from aboveground parts. Ann Bot 82:213-216.

$\rightarrow$ Sakai A, S Sakai, F Akiyama 1997 Do sprouting tree species in erosion-prone sites carry large reserves of resources? Ann Bot 79: 625-630.

$\rightarrow$ Schutte AL, BE van Wyk, J Vlok 1995 Fire survival strategy—a char- acter of taxonomic, ecological, and evolutionary importance in fynbos legumes. Plant Syst Evol 195:243-259.

Schwilk D 2002 Plant evolution in fire-prone environments. PhD diss. Stanford University.

$\rightarrow$ Strang RM 1974 Some man-made changes in successional trends on the Rhodesian highveld. J Appl Ecol 11:249-263.

$\rightarrow$ Thiele K, PY Ladiges 1996 A cladistic analysis of Banksia (Proteaceae). Aust Syst Bot 9:661-733.

$\rightarrow$ Thomas CM, SD Davis 1989 Recovery patterns of three chaparral shrub species after wildfire. Oecologia 80:309-320.

Tiffney BH, KJ Niklas 1985 Clonal growth in land plants: a paleobotanical perspective. Pages 35-66 in JBC Jackson, LW Buss, RE Cook, eds. Population biology and evolution of clonal organisms. Yale University Press, New Haven, Conn.

Trollope WSW 1984 Fire in savanna. Pages 199-218 in P de V Booysen, NM Tainton, eds. Ecological effects of fire in South African ecosystems. Springer, Berlin.

$\rightarrow$ Verdaguer D, F Ojeda F 2002 Root starch storage and allocation patterns in seeder and resprouter seedlings of two Cape Erica (Ericaceae) species. Am J Bot 89:1189-1196.

$\rightarrow$ Verdu M 2000 Ecological and evolutionary differences between Mediterranean seeders and resprouters. J Veg Sci 11:265-268.

$\rightarrow$ Warner RR, PL Chesson 1985 Coexistence mediated by recruitment fluctuations: a field guide to the storage effect. Am Nat 125: 769-787.

$\rightarrow$ Wells PV 1969 The relation between mode of reproduction and extent of speciation in woody genera of the California chaparral. Evolution 23:264-267.

$\rightarrow$ Westoby M 1998 A leaf-height-seed (LHS) plant ecology strategy scheme. Plant Soil 199:213-227.

$\rightarrow$ Westoby M, M Leishman, J Lord 1996 Comparative ecology of seed size and dispersal. Philos Trans R Soc Lond B Biol Sci 351: 1309-1317.

Whelan RJ 1995 The ecology of fire. Cambridge University Press, Cambridge.

Whitehouse C 2003 Systematics of the genus Cliffortia L. (Rosaceae). PhD diss. University of Cape Town.

$\rightarrow$ Wiens D, CL Calvin, CA Wilson, CI Davern, D Frank, SR Seavey 1987 Reproductive success, spontaneous embryo abortion, and genetic load in flowering plants. Oecologia 71:501-509.

$\rightarrow$ Wildy DT, JS Pate 2002 Quantifying above- and below-ground growth responses of the western Australian oil mallee, Eucalyptus kochii subsp. plenissima, to contrasting decapitation regimes. Ann Bot 90:185-197.

$\rightarrow$ Williams RJ, GD Cook, AM Gill, PHR Moore 1999 Fire regime, fire intensity, and tree survival in a tropical savanna in northern Australia. Aust J Ecol 24:50-59.

Wisheu IC, ML Rosenzweig, L Olsvig-Whittaker, A Shmida 2000 What makes nutrient-poor Mediterranean heathlands so rich in plant diversity? Evol Ecol Res 2:935-955. 